\title{
RESEARCH
}

\section{Improved endothelialization of small-diameter ePTFE vascular grafts through growth factor therapy}

\author{
Jarkko P Hytönen ${ }^{1, *}$, Olli Leppänen ${ }^{1, *}$, Jouni Taavitsainen¹, Petra Korpisalo1, Svetlana Laidinen¹, Kari Alitalo², \\ Jonas Wadström³, Tuomas T Rissanen ${ }^{4}$ and Seppo Ylä-Herttuala1,5,6
}

1A.I. Virtanen Institute of Molecular Medicine, University of Eastern Finland, Kuopio, Finland 2Molecular/Cancer Biology Laboratory, Biomedicum Helsinki, Helsinki, Finland

3Department of Transplantation Surgery, Karolinska Hospital Huddinge, Karolinska Institute, Stockholm, Sweden ${ }^{4}$ Heart Centre, North Karelia Central Hospital, Joensuu, Finland

${ }^{5}$ Gene Therapy Unit, Kuopio University Hospital, Kuopio, Finland

${ }^{6}$ Heart Center, Kuopio University Hospital, Kuopio, Finland

Correspondence should be addressed to S Ylä-Herttuala: Seppo.Ylaherttuala@uef.fi

*(J P Hytönen and O Leppänen contributed equally to this work)

\begin{abstract}
Background: Prosthetic vascular grafts in humans characteristically lack confluent endothelialization regardless of the duration of implantation. Use of high-porosity grafts has been proposed as a way to induce endothelialization through transgraft capillarization, although early experiments failed to show increased healing in man.

Objectives: We hypothesized that transduction of tissues around the prosthetic conduit with vectors encoding VEGF receptor-2 (VEGFR2) ligands would augment transinterstitial capillarization and induce luminal endothelialization of high-porosity ePTFE grafts. Methods: Fifty-two NZW rabbits received 87 ePTFE uni- or bilateral end-to-end interposition grafts in carotid arteries. Rabbits were randomized to local therapy with adenoviruses encoding AdVEGF-A165, AdVEGF-A109 or control AdLacZ and analyzed at 6 and 28 days after surgery by contrast-enhanced ultrasound and histology.

Results: AdVEGF-A165 and AdVEGF-A109 dramatically increased perfusion in perigraft tissues at 6 days ( $14.2 \pm 3.6$ or $16.7 \pm 2.6$-fold increases, $P<0.05$ and $P<0.01)$. At 28 days, the effect was no longer significantly higher than baseline. At 6 days, no luminal endothelialization was observed in any of the groups. At 28 days, AdVEGF-A109- and AdVEGF-A165-treated animals showed enhanced ingrowth of transinterstitial capillaries $(66.0 \pm 13.7 \%$ and $77.4 \pm 15.7 \%$ of graft thickness vs $44.7 \pm 24.4 \%$ in controls, $P<0.05)$ and improved luminal endothelialization $(11.2 \pm 26.3 \%$ and $11.4 \pm 22.2 \%$, AdVEGF-A109 and AdVEGF-A165 vs $0 \%$ in controls, $P<0.05$ ). No increased stenosis was observed in the treatment groups as compared to LacZ controls.

Conclusions: This study suggests that transient local overexpression of VEGFR2 ligands in the peri-implant tissues at the time of graft implantation is a novel strategy to increase endothelialization of high-porosity ePTFE vascular grafts and improve the patency of smalldiameter vascular prostheses.
\end{abstract}

(c) 2019 The authors Published by Bioscientifica Ltd
Key Words
- growth factors
- angiogenesis
- blood vessel prosthesis
- endothelium 


\section{Introduction}

Patients who lack autologous venous or arterial bypass conduits cannot be currently offered durable prosthetic alternatives due to poor patency rates of small-diameter $(\leq 6 \mathrm{~mm})$ synthetic vascular grafts (1). In CABG prosthetic conduits are the last option and only seldom used, and in peripheral arterial interventions the problem of poor biocompatibility is commonly exaggerated by suboptimal distal run-off as well as the need for considerable anatomical length of the synthetic vascular substitutes. Moreover, high failure rates of current hemodialysis access grafts continue to be a major problem in the management of end-stage renal disease and better treatments are therefore highly warranted.

Functional vascularization is a fundamental challenge in tissue engineering and most notable successes so far have been in thin or avascular structures such as skin, bladder and cartilage (2). Successful surgical implantation of avascular scaffolds has been reported by implantation alongside a rich external blood supply $(2,3)$. Similarly, endothelialization by transmural capillarization using increased porosity synthetic grafts has been suggested as an alternative way to increase biocompatibility and ultimately improve the patency of prosthetic arterial replacements, such as ePTFE grafts $(4,5)$, which are in broad clinical use and have an outstanding time-proven record against structural degeneration (6). However, early clinical results were discouraging and the findings were proposed to be caused by an insufficient local angiogenic response (7).

Understanding of the key molecular mechanisms of therapeutic neovascularization has improved significantly during the last few years and more mature approaches toward therapeutic applications have emerged. We have consistently shown in normal and ischemic skeletal muscles as well as in myocardium that transient overexpression of VEGF receptor-2 ligands promotes capillary arterialization and sprouting angiogenesis, induces increased blood flow as well as increases the survival and functionality of transferred lymph nodes $(8,9,10,11,12)$. We hypothesized that transient overexpression of VEGF receptor-2 ligands using robust adenovirus vector system, which is locally applied at the time of surgery would stimulate transgraft angiogenesis and luminal endothelialization of smalldiameter high-porosity ePTFE vascular grafts. In addition to substantial preclinical literature over the past two decades using prosthetic graft matrixes impregnated with angiogenic peptides or proteins $(5,13,14,15,16)$ encouraging findings have also been reported with plasmid
DNA, although the results were somewhat conflicting between the used species, graft materials as well as gene doses and combinations (17). In contrast to the results obtained with adenovirus or adeno-associated virus vectors, there is often a lack of dose response effect with plasmid DNA and larger randomized controlled clinical trials have not supported the use angiogenic proteins or plasmid DNA in cardiovascular applications in general $(18,19)$. We used a rabbit carotid artery interposition graft model, which is the recommended small animal system for testing the performance of small-diameter vascular grafts and in which the endothelial response to prosthetic conduits approximates that seen in humans $(20,21)$ : at follow-up, a confluent endothelial layer is limited to the perianastomotic areas of the ePTFE grafts and spontaneous luminal endothelialization through transinterstitial capillarization is characteristically lacking when increased porosity conduits are used in this anatomic region $(22,23)$. Moreover, we hypothesized that ECM-binding motif might influence bioavailability and tissue distribution of ligands using transinterstitial capillarization and luminal endothelialization as read-outs in a graft model of vessel wall assembly (24) and therefore included VEGF core domain (VEGF-A109) which is necessary and sufficient for receptor binding and activation as an additional control. It was shown that local application of adenoviruses encoding either ECM-binding motif containing VEGF-A165 or VEGF-A109 core domain to the peri-conduit tissues at the time of surgery both led to transient increases in perigraft capillarization and perigraft hyperemia, augmented transinterstitial capillarization and induced luminal endothelial cell-mediated healing of the high-porosity small-diameter ePTFE vascular grafts.

\section{Methods}

\section{Graft implantation}

All animal experiments were approved by the Experimental Animal Committee at the University of Eastern Finland. Adult $3.0-4.0 \mathrm{~kg}$ New Zealand white rabbits $(n=52)$ were anesthetized with medetomidine (Domitor, $0.3 \mathrm{mg} / \mathrm{kg}$, Orion, Espoo, Finland) and ketamine (Ketalar, $20 \mathrm{mg} / \mathrm{kg}$, Pfizer). ePTFE $(n=87)$ grafts $(2 \mathrm{~mm}$ internal diameter, $0.35 \mathrm{~mm}$ thick, $30 \mathrm{~mm}$ length, $60 \mu \mathrm{m}$ internodal distance) were implanted into rabbit carotid arteries with continuous 8-0 PTFE sutures in an endto-end anastomosis through a mid-line incision of the neck. The first 17 animals received unilateral prosthesis, 
and when all animals reach the 6 days showing no problems with patency by duplex ultrasonography, the remaining 35 animals received bilateral conduits. Animals received daily enoxaparin $(1 \mathrm{mg} / \mathrm{kg})$ for 6 or 28 days and daily acetylsalicylic acid (10 mg/kg in drinking water) and clopidogrel $(30 \mathrm{mg}$ loading dose followed by $15 \mathrm{mg}$ daily, Plavix, Sanofi) through the follow-up period of 6 or 28 days. Patencies in all cohorts were 100\%. All animals received $125 \mathrm{mg}$ prophylactic single-dose perioperative cefuroxime (Zinacef, GlaxoSmithKline).

\section{Gene transfer}

$1 \times 10^{11}$ viral particles (vp) diluted in $2 \mathrm{~mL}$ of physiological saline of replication-deficient E1-E3-deleted clinical GMPgrade adenoviruses (Ad) encoding VEGF-A109, VEGF-A165 or nuclear-targeted $\beta$-galactosidase ( $L a c Z$ ) marker gene were applied directly into the tissue bed surrounding the prosthesis within a few minutes after reestablishment of arterial blood flow across the carotid artery prosthesis immediately after oozing (if any) of blood through pores of ePTFE graft was ceased. The tissues surrounding the prosthesis were bathed in the solution, and after $15 \mathrm{~min}$, the wound was closed in layers.

\section{Contrast-enhanced ultrasound perfusion imaging}

Perfusion in the perigraft tissues surrounding the grafts and intact carotid arteries was measured with 15L8 transducer (Siemens) using a Cadence Contrast Pulse sequence (CPS) application and SonoVue (Bracco) contrast agent and perfusion ratios between peak intensities comparing perigraft tissue and control carotid were calculated as previously reported (24).

\section{Immunohistochemistry}

Antibodies against endothelial cells (CD31, Dako, 1:50), SMCs (HHF-35, Enzo Biochem, 1:50) and $\beta$-galactosidase (Promega, 1:250) were used along with hematoxylin and eosin (H\&E) stain on $7 \mu \mathrm{m}$ paraffin sections. Images were acquired with an Olympus AX70 microscope (Olympus Optical) and measurements made with analySIS software (Soft Imaging Systems, Munster, Germany).

\section{Capillary measurements and endothelialization}

Capillary measurements from the perigraft tissue were performed from randomly chosen ten images acquired at 200x magnification and analyzed in a blinded manner with analySIS software. Transgraft capillarization was analyzed from 200x magnification images covering the entire graft wall $(4 \mu \mathrm{m}$ thick serial sections, $1 \mathrm{~mm}$ apart covering the $15 \mathrm{~mm}$ mid-graft region) and the mean value for each individual animal was reported as percentage of graft wall thickness traversed by the capillaries from the abluminal surface. Luminal endothelialization was determined from the same serial sections as percentage of the luminal circumference covered by CD31-positive cell lining. Transanastomotic endothelialization was analyzed from longitudinally cut $15 \mathrm{~mm}$ long serial paraffin sections of the anastomoses stained for endothelial cells.

\section{Neointima formation}

Neointimal hyperplasia and graft stenosis was analyzed from HHF-35 stains at mid-graft and expressed as percentage area stenosis (1-(luminal area/graft luminal area) $\times 100$ ). Perianastomotic neointima thickness was determined from longitudinal serial sections of the anastomotic regions.

\section{Statistical analyses}

All parameters were analyzed with one-way ANOVA followed by Dunnett's multiple comparison test comparing AdVEGF-A109 and AdVEGF-A165 treatments to AdLacZ. $P$ values of $<0.05$ were considered significant. All results are reported as mean \pm s.D.

\section{Results}

\section{Transgene expression}

Nuclear-targeted $\beta$-galactosidase expression was detected in perigraft tissues following AdLacZ treatment 6 days after surgery and gene transfer (Fig. 1). No positive cells were seen 4 weeks after gene transfer.

\section{CPS ultrasound}

AdVEGF-A109 and AdVEGF-A165 increased perfusion in perigraft tissue at 6 days $(16.7 \pm 12.3$ or $14.6 \pm 11$. -fold increase vs baseline, $P<0.01$ and $P<0.05$, respectively) (Fig. 2A, B, C, D, E, F, M and P). At 28 days, the effect was attenuated and no longer significantly higher than at baseline (3.6 \pm 4.0 or $2.9 \pm 3.0$-fold increase, $P=\mathrm{NS}$ ). The change in perfusion compared to 0 day baseline was not significant in the control AdLacZ-treated group at either time point $(1.9 \pm 2.3$ and $1.5 \pm 1.7$-fold increase, day 6 and day 28 , respectively, $P=\mathrm{NS}$ ). 

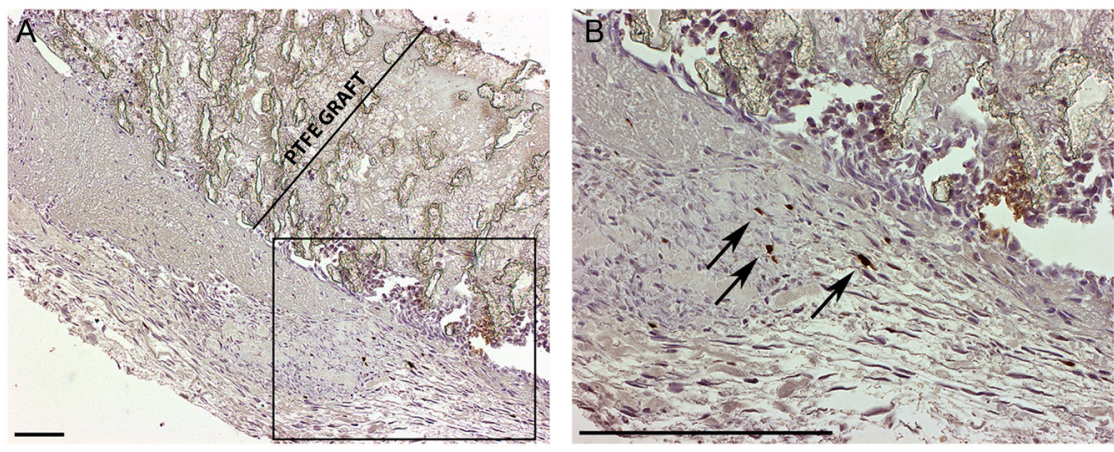

\section{Figure 1}

Marker gene expression. B-galactosidase stain with $40 \times(A)$ and $100 \times(B)$ magnification with $(B)$ showing a higher magnification from the area boxed in (A). The graft wall is marked for clarity in (A). Transduced cells were seen 6 days after surgery and AdLacZ gene transfer (dark brown nuclei indicated with arrows in (B)). Scale bars $200 \mu \mathrm{m}$.

\section{Perigraft tissue capillary size and density}

Six days after treatment (Fig. 2G, H, I, J, K, L, N, O, Q and R) AdVEGF-A treatments increased the size and density of capillaries in the perigraft tissue with strong angiogenesis especially in connective tissue surrounding the grafts. Capillary sizes of $42.4 \pm 32.6,39.6 \pm 8.5$ and $19.3 \pm 6.3 \mu \mathrm{m}$ (AdVEGF-A109, AdVEGF-A165 and LacZ, respectively, $P<0.05$ for AdVEGF-A109 and AdVEGF-A165) were observed. At day 28, the size of the periprosthetic capillaries had reduced, and there were no significant differences between the groups $(22.1 \pm 9.0,18.9 \pm 4.9$ and 22.7 \pm 8.3 for Ad-VEGF-A109, AdVEGF-A165 and AdLacZ, respectively).

Capillary densities at day 6 were (capillaries per $\left.\mathrm{mm}^{2}\right) \quad 917.1 \pm 456.9, \quad 691.5 \pm 210.3$ and $375.5 \pm 181.4$ (AdVEGF-A109, AdVEGF-A165 and LacZ, respectively, $P<0.001$ for AdVEGF-A109 and $P<0.05$ for AdVEGF-A165). No significant differences were seen at the later time point of day $28(655.3 \pm 252.4,757.8 \pm 128.4$ and $735.3 \pm 213.4$ for Ad-VEGF-A109, AdVEGF-A165 and AdLacZ, respectively).

\section{Transanastomotic endothelial growth}

Perianastomotic endothelial cell growth from adjacent arterial segments was determined from longitudinal cross sections of both anastomotic regions 28 days after the gene transfer (Fig. 3). There were no significant differences between the groups in the length of confluent endothelial layer that had extended from the adjacent normal carotid arterial segment to the graft lumen. The distance of endothelial layer from anastomosis was $1.73 \pm 1.23 \mathrm{~mm}$ in AdVEGF-A109-treated animals, $2.14 \pm 1.29 \mathrm{~mm}$ in AdVEGF-A165 group and $2.48 \pm 1.64 \mathrm{~mm}$ in controls, $P=\mathrm{NS}$.

\section{Mid-graft luminal endothelialization}

At mid-graft, no endothelial cells were observed on the luminal surface of the grafts in any of the groups at day 6
(Fig. 4), and by 28 days, no mid-graft luminal endothelium was still present in the control-treated animals. Both AdVEGF-A109 and AdVEGF-A165 groups displayed mid-graft endothelialization at 28 days (11.2 $\pm 26.3 \%$ and $11.4 \pm 22.2 \%$ luminal endothelialization, $P<0.05$, AdVEGF-A109 and AdVEGF-A165, respectively).

\section{Transmural capillary ingrowth}

At day 6, both VEGF-A treatment groups displayed more extensive abluminal penetration of capillaries from the surrounding tissues into the ePTFE graft matrix. $28.2 \pm 15.8 \%$ and 29.4 $27.5 \%$ (AdVEGF-A109 and AdVEGF-A165, $P<0.05$, respectively) of the wall thickness vs $8.9 \pm 12.3 \%$ in control AdLacZ (Fig. 4). Similar effect was observed in the longer follow-up of day 28 with average capillary ingrowth of $66.0 \pm 13.7,77.4 \pm 15.7$ and $44.7 \pm 24.4 \%$ of the graft diameter (AdVEGF-A109, AdVEGF-A165 and LacZ, respectively, $P<0.05$ AdVEGF-A109 and $P<0.001$ AdVEGF-A165).

\section{Restenosis and pannus growth}

Restenosis remained moderate in all groups at day 28 with rates of restenosis of $7.7 \pm 7.5,10.6 \pm 8.6$ and $8.9 \pm 8.7 \%$ of luminal diameter (AdVEGF-A109, AdVEGF-A165 and LacZ, respectively, $P=\mathrm{NS}$ ) (Fig. 5). Neointima/pannus formation at the anastomotic region at day 28 was equally limited with neointima/pannus thickness (in $\mu \mathrm{m}$ ) of $45.4 \pm 45.5$,

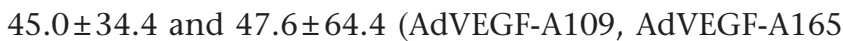
and LacZ, respectively, $P=\mathrm{NS})$.

\section{Discussion}

Insufficient angiogenesis and proliferation or migration of endothelial cells has been suggested as a cause for the lack of transmural endothelialization of high-porosity small caliber synthetic vascular conduits in man $(5,7)$.

This work is licensed under a Creative Commons Attribution-NonCommercial-NoDerivatives 4.0 International License. 

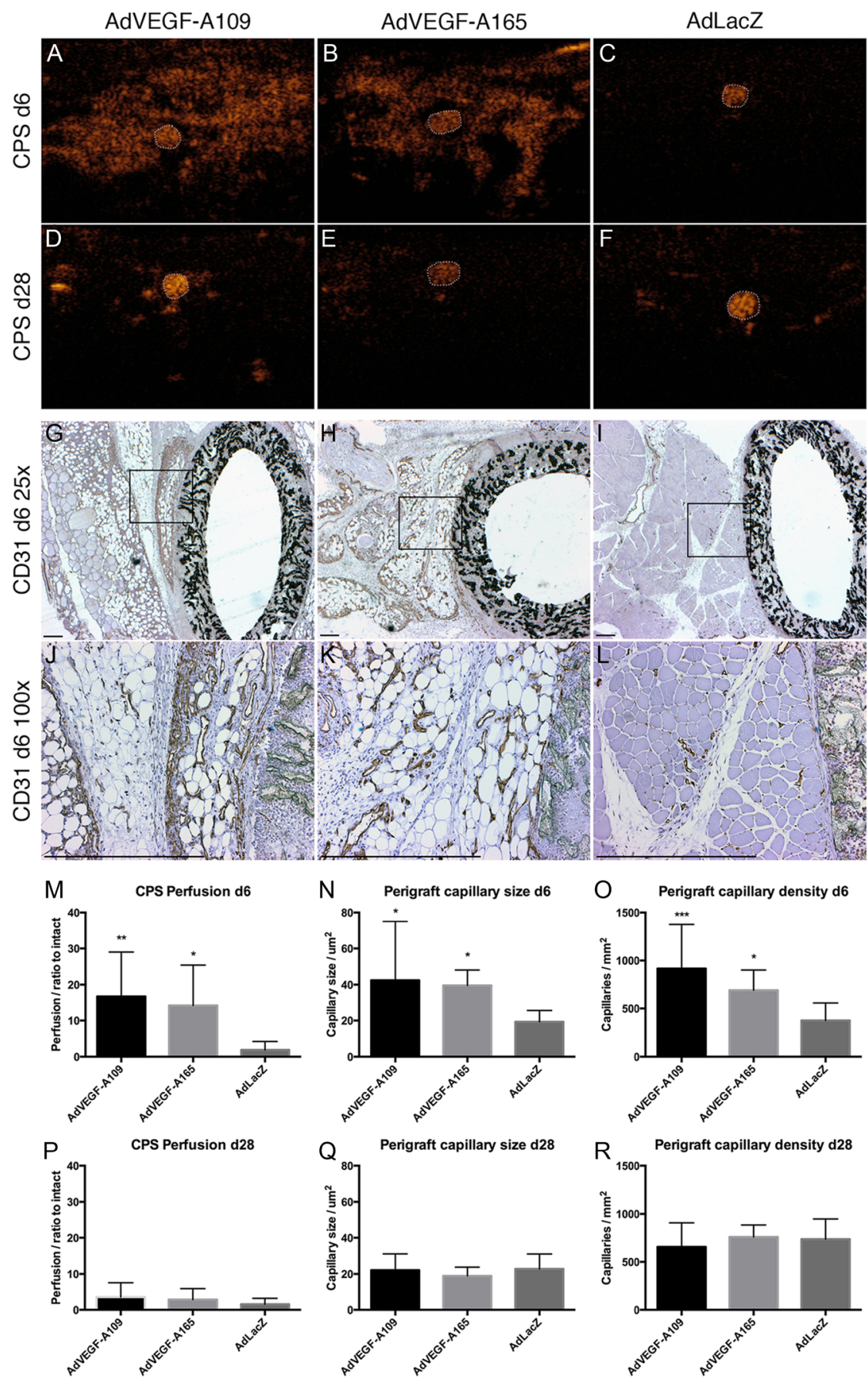

\section{Figure 2}

Perfusion ultrasound and perigraft capillaries. Perfusion ultrasound (A, B, C, D, E and F) and immunohistological staining for endothelial cells $(\mathrm{G}, \mathrm{H}, \mathrm{I}, \mathrm{J}, \mathrm{K}$ and $\mathrm{L})$. CPS ultrasound performed 6 days after gene transfer shows greatly increased perfusion surrounding the graft after treatment with AdVEGF-As (A and B) with contrast agent visible mainly inside the graft lumen in controls (C). At day 28, the perfusion increase has attenuated and a strong signal is only acquired from patent graft lumens (D, E and F). CD31 immunohistology shows an increase in the number and size of adventitial capillaries surrounding the grafts with both AdVEGF-A treatments $(\mathrm{G}, \mathrm{H}$, J and $\mathrm{K})$. At day 6 , both VEGF-A treatments increased perfusion (M) as well as the size $(\mathrm{N})$ and number $(\mathrm{O})$ of adventitial capillaries. These effects were transient and had dissipated by day $28(P, Q$ and $R)$. Graft lumen outlined with dotted white line in $A, B, C, D, E, F$. Box in $G, H, I$ indicates area for higher magnification in J, K, L. Asterisks in $\mathrm{M}, \mathrm{N}, \mathrm{O}, \mathrm{P}, \mathrm{Q}, \mathrm{R}$ indicate significant $P$ values with $* P<0.05, * * P<0.005, * * * P<0.001$. Scale bar $500 \mu \mathrm{m}$ in $\mathrm{G}, \mathrm{H}, \mathrm{I}, \mathrm{J}, \mathrm{K}, \mathrm{L}$.

We demonstrate in a rabbit carotid artery interposition graft model an increase in angiogenesis in the periconduit tissues, accelerated transinterstitial capillarization and improved luminal endothelial cell-mediated healing following local AdVEGF-A109 and AdVEGF-A165 gene transfers performed at the time of graft implantation. The robust boost in angiogenesis is shown both with real-time contrast-enhanced power Doppler ultrasound imaging as increased perigraft blood perfusion and in histology as an increase in the size and number of capillaries in the immediate vicinity of the prosthesis at 6-day time point.

More importantly, the local overexpression of VEGF-As around the ePTFE grafts resulted in an accelerated abluminal entry of capillaries into the graft interstitium. This effect was observed at both time points suggesting that the VEGF-A-induced sprouting angiogenesis and endothelial growth into the graft matrix continued beyond the temporally relatively limited expression period 

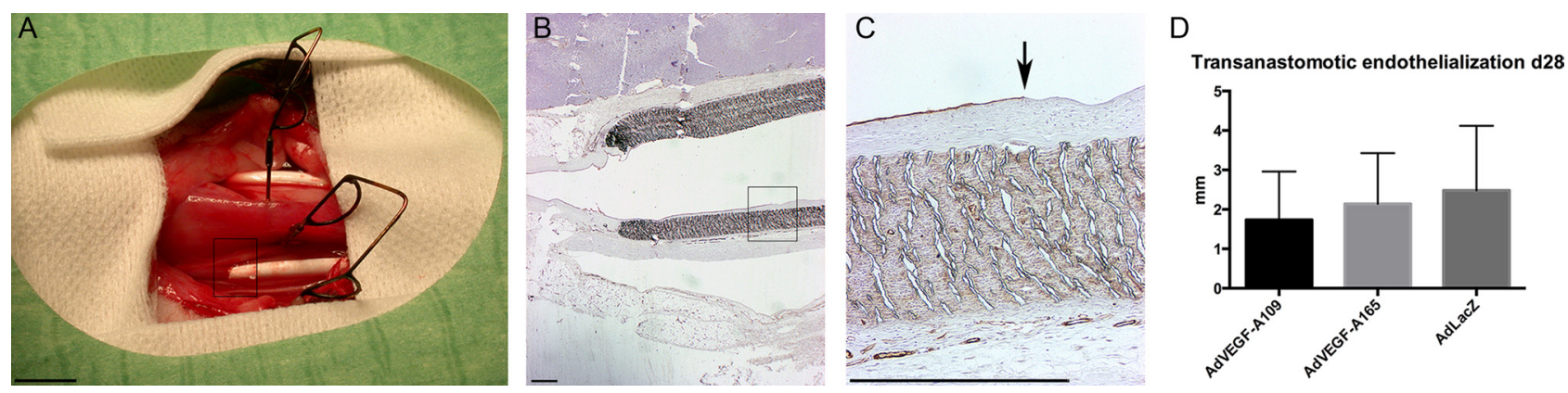

Figure 3

ePTFE grafts in situ and transanastomotic endothelialization. Photograph with bilateral ePTFE grafts in place (A). Endothelialization over the anastomotic site was limited and reached only marginally into the graft. (B and C) CD31 immunohistology for endothelial cells shows the luminal endothelium reaching from the adjacent carotid artery at day 28 (C). There are no significant differences in transanastomotic endothelialization between the groups (D). Arrow marks the edge of the endothelial lining on graft surface in C. Boxes in A and B (40× magnification) shown with higher magnification in C (200x). Scale bar $500 \mu \mathrm{m}$ in B, C.

of AdVEGF-A vector system. Conversely, at 28 days, the capillary size and perfusion did regress in perigraft tissues in both AdVEGF-A groups vs 6 days but perigraft capillary density remained stable in all groups.

At day 28, an increased luminal endothelialization at mid-graft was observed with both AdVEGF-Atreated groups compared with $0 \%$ in the controls. In all animals, the endothelium-covered areas in the mid-graft segments were not confluent with the perianastomotic endothelial growth from adjacent normal artery (data not shown). No differences were observed between the groups in perianastomotic endothelial growth or perianastomotic pannus formation supporting the notion that the increased capillarization was driven by local overexpression of VEGF-As and not by increased systemic VEGF-A levels or by circulating EPCs-driven vascular repair. Only occasional capillaries reached the luminal graft surface and all were found in the AdVEGF-A-treated animals. These penetrating capillaries were found to be confluent with the luminal endothelial cell layer present at mid-graft further supporting the hypothesis that transmural capillaries were the major source of luminal endothelium outside the perianastomotic segments.

Failure of all capillaries in VEGF-A-treated animals to reach full transgraft penetration at 28 days and thereby contribute to luminal endothelialization is likely due to
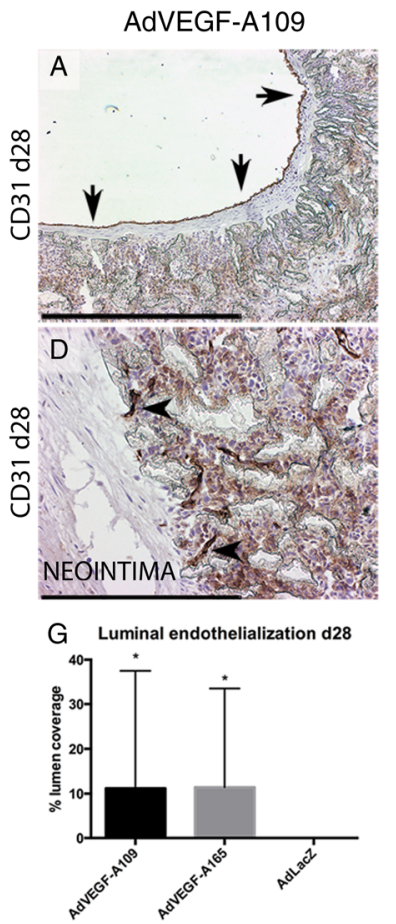

https://vb.bioscientifica.com https://doi.org/10.1530/VB-18-0001
AdVEGF-A165

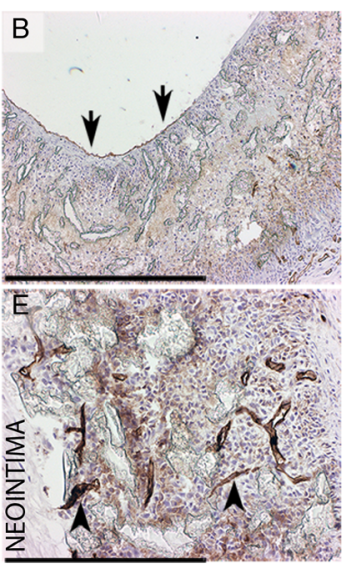

$\mathrm{H} \quad$ Transmural capillary growth $\mathrm{d} 6$

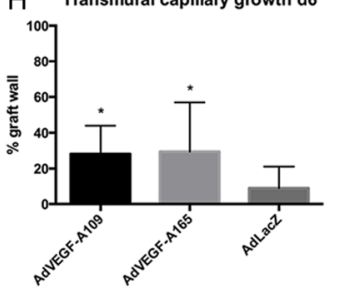

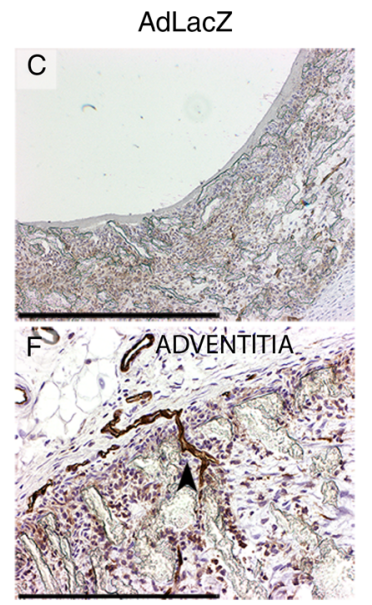

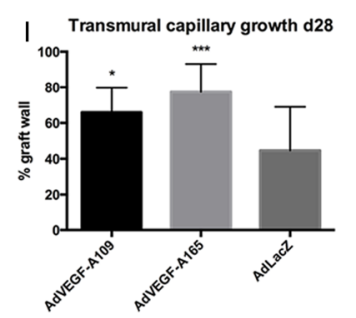

\section{Figure 4}

Lumen and transgraft endothelialization. At day 28 after gene therapy both AdVEGF-A109 (A) and AdVEGF-A165 (B) showed partial endothelialization on the luminal surface of the graft, whereas control AdLacZ (C) remained without endothelium. All grafts showed capillaries growing into the interstitial spaces of the graft wall ( $D, E$ and $F)$. After the AdVEGF-A treatments, endothelial cells were found close to the luminal side of the grafts (left side of image $D$ and $E$ ) while positive staining was restricted more adventitially with control AdLacz (F). The total degree of luminal endothelialization $(\mathrm{G})$ as well as transmural capillary growth $(\mathrm{H}, \mathrm{I})$ were significantly improved in both AdVEGF-A treatment groups. Scale bar $500 \mu \mathrm{m}$ in A, B, C, D, $E, F$. Asterisks in $G, H$, I indicate significant $P$ values with $* P<0.05, * * P<0.005, * * * P<0.001$. (c) 2019 The authors Published by Bioscientifica Ltd
This work is licensed under a Creative Commons Attribution-NonCommercial-NoDerivatives 4.0 International License.

ded from Bioscientifica.com at 04/26/2023 08:58:39AM 

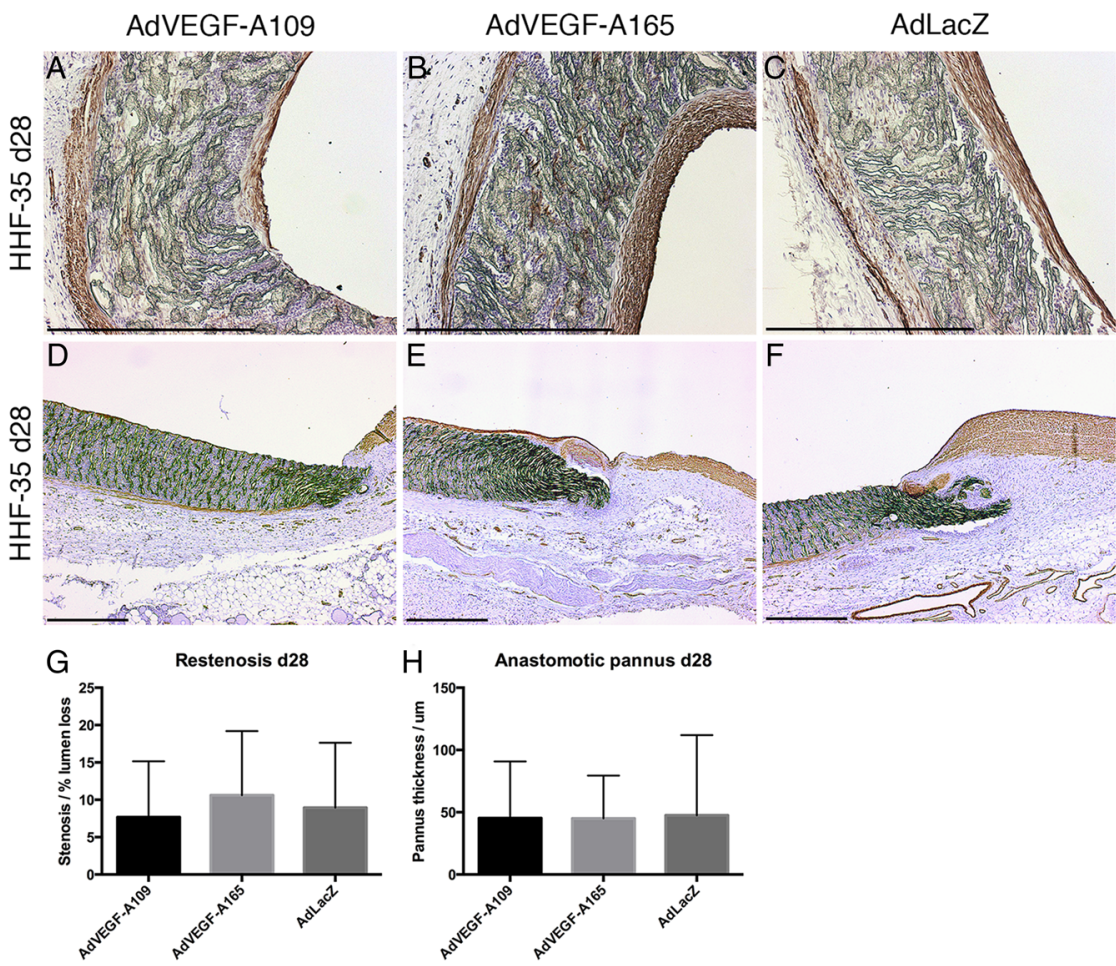

\section{Figure 5}

Neointima and pannus formation. At day 28 , grafts in all groups had developed a thin layer of mostly smooth muscle cell neointima as shown by HHF-35 stain (A, B and C). Anastomotic areas show an unobstructive pannus formation (D, E and F). Neither mid-graft restenosis by neointimal growth nor the formation of an anastomotic pannus was statistically different between the groups ( $G$ and H). Scale bar $500 \mu \mathrm{m}$ in A, B, C, D, E, F.

locally heterogenic oxygen diffusion from the carotid lumen and insufficient hypoxic gradients driving the direction of capillary growth. In sprouting angiogenesis, capillary endothelial cells generally migrate toward a higher VEGF concentration, and angiogenesis is a heavily hypoxia-driven process. In normal and atherosclerotic rabbit carotid arteries, the hypoxic area is deep in the medial layer (25) and in the center of the atherosclerotic plaque $(26,27)$, respectively. Similarly, in the prosthetic conduit, the hypoxic center is likely to move toward the lumen, but finally reach the diffusion of oxygen and nutrients from the carotid lumen. Indeed, the growth of capillaries seemed to have reached a plateau in most treated grafts just before the luminal surface with only occasional capillaries penetrating the entire transmural length of the graft. A detailed molecular characterization of this capillary population is a valid target for ongoing and future research to find novel therapeutic targets in tissue engineering and therapeutic angiogenesis research in general. Moreover, virus application needs to be better characterized and standardized before clinical development. The tissue composition surrounding implants is heterogenous between different anatomical locations and individual patients and is likely to influence not only the local spatial distribution of the therapeutic protein expression (11) but also the degree of capillary invasion of the ePTFE matrix (28), although no correlation was found in our study between luminal endothelialization or transmural capillary ingrowth and the degree of coverage of different tissues in contact with the prosthesis at explantation (data not shown). Furthermore, simple 'bathing' of surrounding tissues results in wider local transgene expression and vascular growth ( $>1 \mathrm{~cm}$ from the implant; Fig. 2) that is likely to be necessary to stimulate capillary formation in the immediate vicinity of the graft. Now, tissue edema from VEGF-A-induced vascular permeability is transiently formed at the site of virus application $(11,29)$, which is highly deleterious in typical clinical situation further impairing tissue oxygenation in an already ischemic tissue. Definition of the minimal target tissue volume around the prosthetic vascular graft as well as appropriate virus formulation for this application needs to be developed to improve efficacy and limit side effects.

Adventitial VEGF-A has been shown to be an accelerator of neointimal hyperplasia (30). The present study found, however, no increased neointimal formation or accelerated pannus formation in the AdVEGF-A-treated groups compared to the control. In atherosclerotic lesions, vasa vasorum vessels appear to feed the growing plaque. In the current setting of ePTFE graft functionalization, the increased capillary network showed only beneficial effects in the form of partial luminal endothelialization and increased transmural growth. The local milieu surrounding 
the engineered graft differs therefore significantly from native artery. Moreover, it is also important to understand that ePTFE itself presents a very harsh microenvironment for proper endothelial cell-mediated healing and better materials and material coatings are highly warranted to support capillary ingrowth and ultimately luminal endothelialization (5).

In conclusion, our results suggest that angiogenic gene therapy applied directly on the surgical wound at the time of graft placement may be beneficial in improving the currently very poor patency rates of the smalldiameter vascular conduits. Together with novel graft material research with improved biocompatibility profiles that support neocapillaries, this approach has therapeutic potential to improve the significant clinical problem of poor endothelialization and currently dismal patency of small-diameter vascular grafts.

\section{Declaration of interest}

Dr Seppo Ylä-Herttuala is an editorial board member of Vascular Biology. Dr Seppo Ylä-Herttuala was not involved in the review or editorial process for this paper, on which he is listed as an author. The other authors have no relationship with industry or other conflicts of interest to disclose.

\section{Funding}

This work was supported by grants from the Finnish Academy, Kuopio University Hospital, the Finnish Cultural Foundation North Savo Regional Fund, The Paulo Foundation, Aarne Koskelo Foundation and Ida Montin foundation.

\section{References}

1 Seifu DG, Purnama A, Mequanint K \& Mantovani D. Small-diameter vascular tissue engineering. Nature Reviews Cardiology 201310 410-421 (https://doi.org/10.1038/nrcardio.2013.77)

2 Place ES, Evans ND \& Stevens MM. Complexity in biomaterials for tissue engineering. Nature Materials 20098 457-470. (https://doi. org/10.1038/nmat2441)

3 Atala A, Bauer SB, Soker S, Yoo JJ \& Retik AB. Tissue-engineered autologous bladders for patients needing cystoplasty. Lancet 2006 367 1241-1246. (https://doi.org/10.1016/S0140-6736(06)68438-9)

4 Clowes AW, Kirkman TR \& Reidy MA. Mechanisms of arterial graft healing. Rapid transmural capillary ingrowth provides a source of intimal endothelium and smooth muscle in porous PTFE prostheses. American Journal of Pathology 1986123 220-230.

5 Zilla P, Bezuidenhout D \& Human P. Prosthetic vascular grafts: wrong models, wrong questions and no healing. Biomaterials $2007 \mathbf{2 8}$ 5009-5027. (https://doi.org/10.1016/j.biomaterials.2007.07.017)

6 Stollwerck PL, Kozlowski B, Sandmann W, Grabitz K \& Pfeiffer TJ. Long-term dilatation of polyester and expanded polytetrafluoroethylene tube grafts after open repair of infrarenal abdominal aortic aneurysms. Journal of Vascular Surgery 201153 1506-1513. (https://doi.org/10.1016/j.jvs.2011.02.028)
7 Kohler TR, Stratton JR, Kirkman TR, Johansen KH, Zierler BK \& Clowes AW. Conventional versus high-porosity polytetrafluoroethylene grafts: clinical evaluation. Surgery 1992112 901-907.

8 Rissanen TT, Korpisalo P, Markkanen JE, Liimatainen T, Ordén MR, Kholová I, de Goede A, Heikura T, Gröhn OH \& YläHerttuala S. Blood flow remodels growing vasculature during vascular endothelial growth factor gene therapy and determines between capillary arterialization and sprouting angiogenesis. Circulation 2005112 3937-3946. (https://doi.org/10.1161/ CIRCULATIONAHA.105.543124)

9 Korpisalo P, Karvinen H, Rissanen TT, Kilpijoki J, Marjomäki V, Baluk P, McDonald DM, Cao Y, Eriksson U, Alitalo K, et al. Vascular endothelial growth factor-A and platelet-derived growth factor-B combination gene therapy prolongs angiogenic effects via recruitment of interstitial mononuclear cells and paracrine effects rather than improved pericyte coverage of angiogenic vessels. Circulation Research 2008103 1092-1099. (https://doi.org/10.1161/ CIRCRESAHA.108.182287)

10 Lähteenvuo JE, Lähteenvuo MT, Kivelä A, Rosenlew C, Falkevall A, Klar J, Heikura T, Rissanen TT, Vähäkangas E, Korpisalo P, et al. Vascular endothelial growth factor-B induces myocardium-specific angiogenesis and arteriogenesis via vascular endothelial growth factor receptor-1- and neuropilin receptor-1-dependent mechanisms. Circulation 2009119 845-856. (https://doi.org/10.1161/ CIRCULATIONAHA.108.816454)

11 Korpisalo P, Hytönen JP, Laitinen JT, Laidinen S, Parviainen H, Karvinen H, Siponen J, Marjomäki V, Vajanto I, Rissanen TT, et al. Capillary enlargement, not sprouting angiogenesis, determines beneficial therapeutic effects and side effects of angiogenic gene therapy. European Heart Journal 201132 1664-1672. (https://doi. org/10.1093/eurheartj/ehq433)

12 Lähteenvuo M, Honkonen K, Tervala T, Tammela T, Suominen E, Lähteenvuo J, Kholová I, Alitalo K, Ylä-Herttuala S \& Saaristo A. Growth factor therapy and autologous lymph node transfer in lymphedema. Circulation 2011123 613-620. (https://doi. org/10.1161/CIRCULATIONAHA.110.965384)

13 Greisler HP, Cziperle DJ, Kim DU, Garfield JD, Petsikas D, Murchan PM, Applegren EO, Drohan W \& Burgess WH. Enhanced endothelialization of expanded polytetrafluoroethylene grafts by fibroblast growth factor type 1 pretreatment. Surgery 1992112 244-254.

14 Brewster LP, Bufallino D, Ucuzian A \& Greisler HP. Growing a living blood vessel: insights for the second hundred years. Biomaterials 200728 5028-5032. (https://doi.org/10.1016/j. biomaterials.2007.07.048)

15 Antonova LV, Seifalian AM, Kutikhin AG, Sevostyanova VV, Matveeva VG, Velikanova EA, Mironov AV, Shabaev AR, Glushkova TV, Senokosova EA, et al. Conjugation with RGD peptides and incorporation of vascular endothelial growth factor are equally efficient for biofunctionalization of tissue-engineered vascular grafts. International Journal of Molecular Sciences 201617 E1920. (https://doi. org/10.3390/ijms17111920)

16 Shafiq M, Zhang Q, Zhi D, Wang K, Kong D, Kim DH \& Kim SH. In situ blood vessel regeneration using SP (substance P) and SDF (stromal cell-derived factor)-1 $\alpha$ peptide eluting vascular grafts. Arteriosclerosis, Thrombosis, and Vascular Biology 201838 e117-e134. (https://doi.org/10.1161/ATVBAHA.118.310934)

17 Lahtinen M, Blomberg P, Baliulis G, Carlsson F, Khamis H \& Zemgulis V. In vivo h-VEGF165 gene transfer improves early endothelialisation and patency in synthetic vascular grafts. European Journal of Cardio-Thoracic Surgery 200731 383-390. (https://doi. org/10.1016/j.ejcts.2006.11.048)

18 Rissanen TT \& Ylä-Herttuala S. Current status of cardiovascular gene therapy. Molecular Therapy 200715 1233-1247. (https://doi. org/10.1038/sj.mt.6300175) 
19 Ylä-Herttuala S \& Baker AH. Cardiovascular gene therapy: past, present, and future. Molecular Therapy 201725 1095-1106. (https:// doi.org/10.1016/j.ymthe.2017.03.027)

20 Kerdjoudj H, Berthelemy N, Rinckenbach S, Kearney-Schwartz A, Montagne K, Schaaf P, Lacolley P, Stoltz JF, Voegel JC \& Menu P. Small vessel replacement by human umbilical arteries with polyelectrolyte film-treated arteries: in vivo behavior. Journal of the American College of Cardiology 200852 1589-1597. (https://doi. org/10.1016/j.jacc.2008.08.009)

21 Byrom MJ, Bannon PG, White GH \& Ng MK. Animal models for the assessment of novel vascular conduits. Journal of Vascular Surgery 201052 176-195. (https://doi.org/10.1016/j.jvs.2009.10.080)

22 Sparks SR, Tripathy U, Broudy A, Bergan JJ, Kumins NH \& Owens EL. Small-caliber mesothelial cell-layered polytetraflouroethylene vascular grafts in New Zealand white rabbits. Annals of Vascular Surgery 200216 73-76. (https://doi.org/10.1007/s10016-001-0133-5)

23 Contreras MA, Quist WC \& Logerfo FW. Effect of porosity on small-diameter vascular graft healing. Microsurgery 200020 15-21. (https://doi.org/10.1002/(SICI)1098-2752(2000)20:1<15::AIDMICR3>3.0.CO;2-P)

24 Kraiss LW, Raines EW \& Wilcox JN. Regional expression of the platelet-derived growth factor and its receptors in a primate graft model of vessel wall assembly. Journal of Clinical Investigation 199392 338-348. (https://doi.org/10.1172/JCI116572)

25 Rissanen TT, Korpisalo P, Karvinen H, Liimatainen T, Laidinen S, Gröhn $\mathrm{OH} \&$ Ylä-Herttuala S. High-resolution ultrasound perfusion imaging of therapeutic angiogenesis. JACC Cardiovasc Imaging 2008 83-91. (https://doi.org/10.1016/j.jcmg.2007.10.009)
26 Levin M, Leppänen O, Evaldsson M, Wiklund O, Bondjers G \& Björnheden T. Mapping of ATP, glucose, glycogen, and lactate concentrations within the arterial wall. Arteriosclerosis, Thrombosis, and Vascular Biology 200323 1801-1807. (https://doi.org/10.1161/01. ATV.0000092872.54026.8D)

27 Leppänen O, Björnheden T, Evaldsson M, Borén J, Wiklund $\mathrm{O} \&$ Levin M. ATP depletion in macrophages in the core of advanced rabbit atherosclerotic plaques in vivo. Atherosclerosis $2006 \mathbf{1 8 8} 323-330$. (https://doi.org/10.1016/j. atherosclerosis.2005.11.017)

28 Hazama K, Nishibe T, Shimada T, Miura H, Watanabe S, Kondoh S, Takahashi T, Okuda Y \& Katoh H. Effects of omental wrap on performance of small-caliber high-porosity expanded polytetrafluoroethylene grafts. Journal of Surgical Research $1999 \mathbf{8 1}$ 174-180. (https://doi.org/10.1006/jsre.1998.5497)

29 Vajanto I, Rissanen TT, Rutanen J, Hiltunen MO, Tuomisto TT, Arve K, Närvänen $\mathrm{O}$, Manninen $\mathrm{H}$, Räsänen $\mathrm{H}$, Hippeläinen M, Alhava E, et al. Evaluation of angiogenesis and side effects in ischemic rabbit hindlimbs after intramuscular injection of adenoviral vectors encoding VEGF and LacZ. Journal of Gene Medicine 20024 371-380. (https://doi.org/10.1002/jgm.287)

30 Sluimer JC, Gasc JM, van Wanroij JL, Kisters N, Groeneweg M, Sollewijn Gelpke MD, Cleutjens JP, van den Akker LH, Corvol P, Wouters BG, et al. Hypoxia, hypoxia-inducible transcription factor, and macrophages in human atherosclerotic plaques are correlated with intraplaque angiogenesis. Journal of the American College of Cardiology 200851 1258-1265. (https://doi.org/10.1016/j. jacc.2007.12.025)

Received in final form 30 November 2018 Accepted 6 December 2018 (c) 2019 The authors Published by Bioscientifica Ltd
This work is licensed under a Creative Commons Attribution-NonCommercial-NoDerivatives 4.0 International License. ded from Bioscientifica,com at 04/26/2023 08:58:39AM 